\title{
Application of semi-microcolumn liquid chromatography to forensic analysis
}

\author{
O. Shirota, A. Suzuki, T. Ogawa and Y. Ohtsu
}

Shiseido Research Center, 1050 Nippacho, Kohoku, Yokohama 223, Japan

Semi-microcolumn liquid chromatography with a column-switching system was applied to the analysis of methamphetamine enantiomers and its metabolites.

\section{Semi-microcolumn Liquid Chromatography}

Attempts to miniaturize columns for liquid chromatography (LC) have been reported since the late 70's [1-5]. A series of advantages were repeatedly demonstrated in the use of microcolumns, whose inner diameters were less than $1 \mathrm{~mm}$. However, several requirements and limitations have kept microcolumn LC mostly in the area of basic research. On the contrary, semi-microcolumn LC (inner diameter: 1$2 \mathrm{~mm}$ ) has been widely accepted in academia and industry, possessing both advantages shown by microcolumn LC and reliability of conventional LC.

\section{Column-Switching System}

Although certain modifications, such as miniaturizing dead volumes of components, are required in an instrumental arrangement [3], it became possible to easily obtain a highly efficient separation with a semi-microcolumn even under isocratic conditions (Fig. 1). Benefits of semi-microcolumn LC seemed most pronouncing when a columnswitching system was arranged [6] (Fig. 2). A tremendous concentrating effect could be earned by first injecting a relatively large volume of sample solution $(50-100 \mu \mathrm{L})$ to a short conventional-bore precolumn, and then transferring an analyte-containing fraction to a semi-microcolumn connected to a detector. The analytical format was applied to analysis of various substances contained in biological liquids at very low concentrations [7-9]. The rest of the short article will mainly discuss its application to forensic analysis.

\section{Analysis of methamphetamine (MA)}

Drug abuse, causing damages on personality as well as a number of related crimes, has become one of the most serious social problems in all area of the developed world. At present, $d$-methamphetamine ( $d$-MA) hydrochloride is extensively used in most cases of drug abuse. In the analysis of controlled substances, it is critically important to rapidly ensure the identification of drugs remained in the body of abusers. The column switching system based on semi-microcolumn appeared useful in that it does not require a complicated sample pre-treatment and that the analyte is detected under a concentrating effect of a semimicrocolumn [10-12].

A column switching system consisting of a pre-separation column $(4.0 \mathrm{~mm}$ i.d. $\times 10 \mathrm{~mm})$ designed for deproteinization $[13,14]$ and a semi-microcolumn $(1.5 \mathrm{~mm}$ i.d. $\times$ $250 \mathrm{~mm}$ ) for the main separation (similar to the one shown 
in Fig. 2) was applied to forensic analysis. A trace amount of MA $(1 \mu \mathrm{g} / \mathrm{mL})$ contained in human urine sample was successfully detected with a good linearity and reproducibility in the system [10].

Another requirement was recently added on MA analysis. As mentioned earlier, abused MA is mainly in the form of $d$-enantiomer. On the other hand, $l$-MA, its another enantiomer, has already been approved as antiparkinsonism drug in several countries [15]. Therefore, from now on, forensic analysis has to have a capability to distinguish the illicit use of $d$-MA from the medical use of $l$-MA. One of the solutions to this problem was to prepare a separation column providing an optical resolution for the enantiomers. A semi-microcolumn based on phenyl- $\beta$-cyclodextrin was prepared for this purpose. The separation of MA enantiomers and amphetamine (AP), a metabolite of MA on such semi-microcolumn is shown in figure 3. Both substances were base-line separated within an acceptably short period.

The use of the $\beta$-cyclodextrin column in the column switching system was expected to meet the requirements of the new MA analysis. Attempts to further obtain sensitivity and/or selectivity with a diode array detector ${ }^{11}$ and a mass spectrometer [12] in addition to the optical resolution

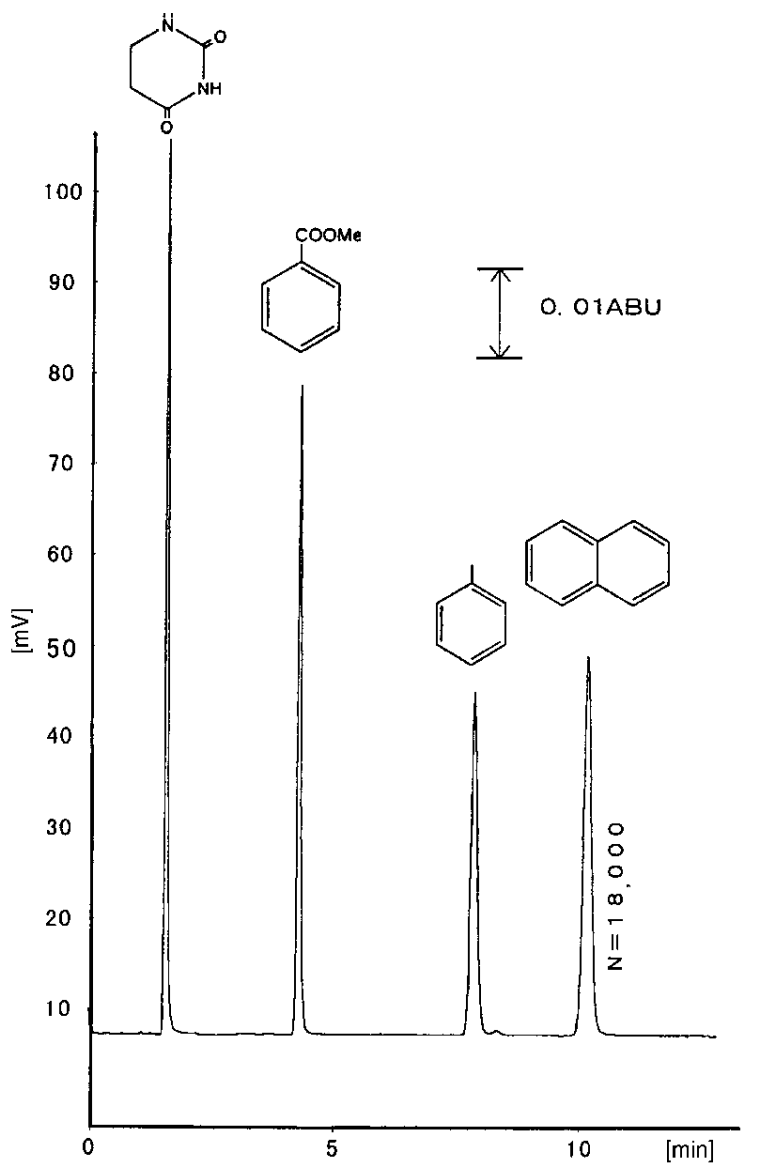

Figure 1. Separation of standard mixture with $1.5-\mathrm{mm}$ i.d. semimicrocolumn. Column: Capcell Pak C18 UG120 S3, $1.5 \mathrm{~mm}$ i.d. $\times 150 \mathrm{~mm}$. Mobile phase: acetonitrile 55\%. Detection: UV, $254 \mathrm{~nm}$. Oven temp.: $40{ }^{\circ} \mathrm{C}$. Samples: uracil, methyl benzoate, toluene, naphthalene.

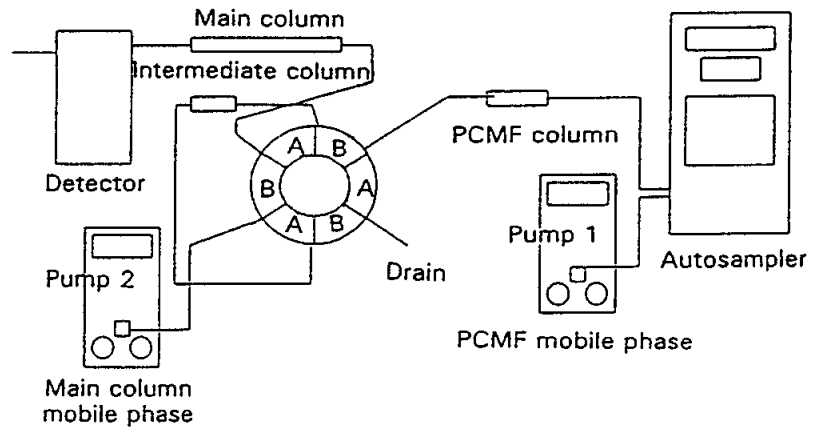

Valve status $A$

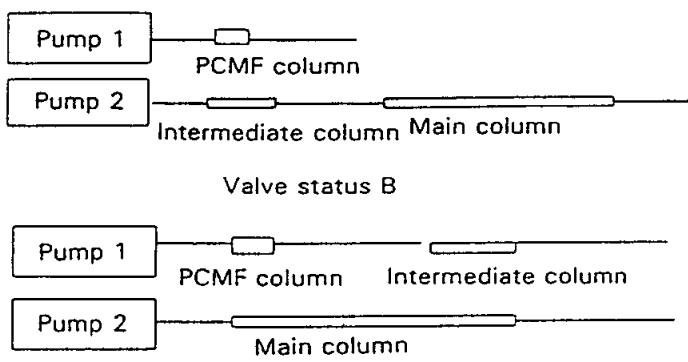

Figure 2. Schematic diagram of triple-column system. The connection of pumps and column for each valve status is indicated in the lower diagram. Analytes are concentrated in the intermediate column in status $B$, and then transferred to the main separation column when it is switched back to status $A$ (Reproduced from Ref. 9).

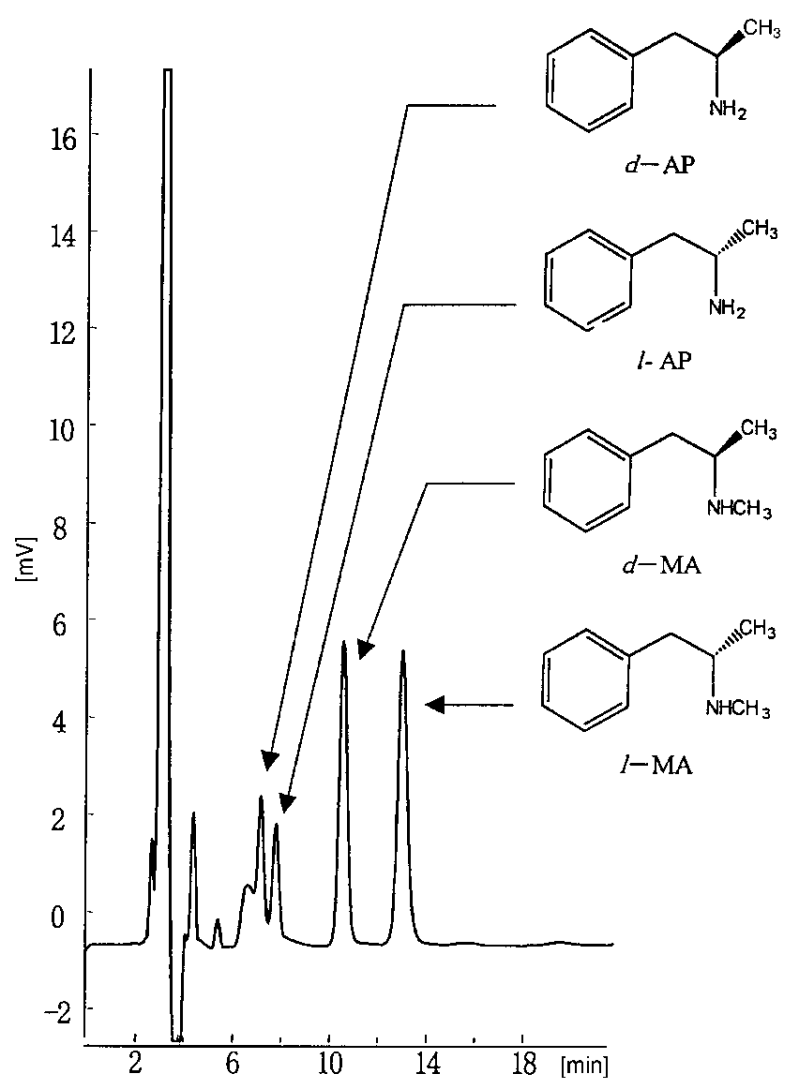

Figure 3. Separation of MA and AP enantiomers on $\beta$-CD semimicrocolumn. Column: Phenyl $\beta-C D$ (Shiseido), $2.0 \mathrm{~mm}$ i.d. $\times$ $250 \mathrm{~mm}$. Mobile phase: $50 \mathrm{mM}$ phosphate buffer $(\mathrm{pH} \mathrm{4.6)/} \mathrm{ace-}$ tonitrile $=70 / 30$. Oven temp.: $40^{\circ} \mathrm{C}$. 
were reported. The system with a diode array detector could analyze MA enantiomers with spectral information at the detection limit of $1 \mu \mathrm{g} / \mathrm{mL}$. Since the concentration of MA left in abusers' urine ranges approximately from 1 to $100 \mu \mathrm{g} / \mathrm{mL}$, the sensitivity obtained at the system seem adequate for their application to forensic analysis.

Furthermore, the system with a mass spectrometer equipped with electrospray ionization could detect each MA enantiomer down to $1 \mathrm{ng} / \mathrm{mL}$ [12]. One of the advantages of a narrow-bore LC, when connected to a mass spectrometer, is that the weight ratio of analyte over a mobile phase flowing into an ionization chamber is largely increased, which leads to a substantial decrease in chemical noise on a spectrum and a chromatogram. While a mass spectrometer is still one order of the magnitude more expensive than other LC detectors, a progress in ionization technology and a tendency of falling price are gradually making it more accessible to many areas. Applications of semi-microcolumn LC to LC/MS are expected to be more frequent in the near future.

The semi-microcolumn LC is now being applied to other controlled substances, such as cocaine, codeine, and hemprelated substances. Although other microcolumn separation techniques represented by capillary electrophoresis have demonstrated an impressive sensitivity in many applications, the system described here, providing a high "concentration sensitivity" seems the most suitable in confronting low-concentration samples in forensic analysis.

\section{References}

1. Scott, R. P. W.; Kucera, P. J. J. Chromatogr. 1976, 125, 27.

2. Tsuda, T.; Novotny, M. V. Anal. Chem. 1978, 50, 271.

3. Novotny, M. V. Anal. Chem. 1988, 60, 500A.

4. Takeuchi, T.; Yeung, E. S. J. Chromatogr. 1987, 389, 3.

5. Takeuchi, T.; Miwa, T. Chromatographia 1995, 40, 545.

6. Shirota, O.; Suzuki, A.; Kanda, T.; Ohtsu, Y.; Yamaguchi, M. J. Microcol. Sep. 1995, 7, 29.

7. Kanda, T.; Shirota, O.; Ohtsu, Y.; Yamaguchi M. J. Microcol. Sep. 1995, 7, 445.

8. Kanda, T.; Ohtsu, Y. Rinsyou Kagaku, in press.

9. Sato, M.; Yoshimura, H.; Shimmura, T.; Obi, H.; Hatayama, S.; Kaneko, E.; Hoshino, H.; Yotsuyanagi, T. J. Chromatogr. 1997, 789, 361.

10. Shirota, O.; Suzuki, A, Ohtsu, Y.; Makino, Y.; Ohta, S.; Hirobe, M. Chromatography 1996, 17, 189.

11. Suzuki, A.; Shirota, O.; Ohtsu, Y.; Makino, Y.; Ohta, S.; Nagano, T. Chromatography 1997, 17, 21.

12. Katagi, M.; Nishikawa, M.; Tatsuno, M.; Miyagawa, T.; Tsuchihashi, H.; Suzuki, A.; Shirota, O. Eisei Kagaku, in press.

13. Kanda, T.; Kutsuna, H.; Ohtsu, Y.; Yamaguchi, M. J. Chromatogr. A 1994, 672, 51.

14. Kanda, T.; Shirota, O.; Ohtsu, Y.; Yamaguchi, M. J. Chromatogr. A 1996, 722, 115.

15. Reynolds, G. P.; Rieder, P.; Sandler, M.; Jellinger, K.; Seeman, D. J. Neutral Transm. 1978, 43, 271. 